\title{
Mathematical modeling of multimodal transportation in Ukraine using methods of the graph theory
}

\author{
Iryna Perevozova ${ }^{1, *}$, Svitlana Minakova ${ }^{1}$, Khrystyna Obelnytska $^{1}$, Liliya Mykhailyshyn ${ }^{2}$, \\ and Olena Morozova ${ }^{2}$ \\ ${ }^{1}$ Ivano-Frankivsk National Technical Oil and Gas University, Department of Entrepreneurship and \\ Marketing, 76019 Ivano-Frankivsk, Ukraine \\ ${ }^{2}$ Vasyl Stefanyk Precarpathian National University, Department of International Economic Relations, \\ 76018 Ivano-Frankivsk, Ukraine
}

\begin{abstract}
One of the problems of modernizing multimodal transportation of goods in post-Soviet countries is the optimization of the transport supply chain. This requires, in particular, a software package that is to be adapted to local conditions, to the expanded set of risks and the need, in general, to perform optimization on the base of fuzzy data. When choosing the objective function, it is necessary to take into account not only the cost of the specific option of route, the time of transportation, but also the degree of reliability of both the contractors and the infrastructure. For creating a mathematical model were used graph theory and fuzzy logic. Separate types of transport are considered as directed graphs. The set of directed graphs of modes of transport is a multidimensional graph, under the presence of connecting arcs between their nodes. These nodes represent the points of transshipment. The software package assesses the reliability of each section of the supply chain. The developed software package using the proposed mathematical model will allow improving multimodal transportation of goods.
\end{abstract}

\section{Introduction}

Ukraine is rapidly integrating into the world economy. Geographic location of the country, proximity to European transport corridors makes it a promising transport hub. The developed network of seaports, railways, motorways, pipelines and aviation transport allowed Ukraine to play the role of a transport hub for the USSR, being its part, to meet the needs for multimodal transport of its own market. But, nowadays, transport infrastructure, legislative support, transport logistics need to be modernized. First of all, planning and forecasting of the risks of multimodal transportation require such modernization. For qualitative planning and forecasting of the risks of multimodal transportation, there was a need to develop software and a mathematical core that would be adapted to the realities of the Ukrainian transportation system.

\footnotetext{
*Corresponding author: perevozova@ukr.net
} 
The planning and forecasting of transport risks have been long and widely used by various countries throughout the world [1, 2, 3, 4]. These functions are included into application packages. The problem of direct application of such software in Ukraine is associated with the necessity of its adaptation to the conditions of practical implementation. A set of transportation risks, for example, is wider than that for developed economies.

In Ukraine, computerized decision support systems (SPDRs) were also introduced into practical operation for the transportation of goods, their transshipment, the choice of the most efficient routes $[5,6]$. These systems proved to be reliable basing on the experience of operation of transport organizations of the USSR. However, the conditions of transportation, too big data sets, inherent to the modern operation of transport systems, capabilities of modern computer technologies require new mathematical approaches to the formation of the core of SPDR computer software [7, 8].

In addition, the practical operation of various software systems aimed at finding the optimal route for the transportation of goods by different modes of transport, in the presence of transit points for their transshipment, in the case of large databases, shows that there is still a need to create a mathematical model that would allow them to carry out efficiently and with minimal load of computer resources to perform such calculations [9, $10,11,12]$.

Therefore, the purpose of this work was to develop such a mathematical model of software packages of SPDR multimodal transport, which would meet the modern requirements of multimodal transportation in Eastern European countries, in particular, in Ukraine.

\section{The mathematical modeling of multimodal transportation}

An array of destinations, intermediate points of overload and points of dispatch of cargoes by each type of transport: sea, river, railway, automobile, aviation, pipeline or other are considered as an array of vertices (nodes) of directed graph. This directed graph (digraph) can take both a canonical and a non-canonical form.

A consistent set of ribs (arcs) linking specific points of dispatch and the destination of the cargo is named "way". For each of the arcs a set of parameters is given: the cost of the operation (transportation or overload), the time of operation (transportation or overload), etc. Obviously, the set of these arrays, uniting separate arrays attributed to individual mode of transport, is a multidimensional array. The requirement to the existence of a multidimensional array will be the presence of at least one edge (arc) of the relationship between the vertices of the specified arrays. In general case, the relationship between the vertices of the specified arrays is not an arc, but a tree of possibilities (implementation options). The specified multidimensional array, in general case, will be classified as a large system, or as a large set of data - big data.

In the case of using a matrix analysis for each of the possible digraphs by type of transport, we form an incidence matrix. The matrix of the incision of the digraph, subject to the presence in the orthograph $q$ tops and $w$ arcs is a matrix of size $q \times w$, elements of which $a_{i j}$ meet the requirement:

$$
a_{i j}=\left\{\begin{array}{c}
1 \text { when for the } \mathrm{i}-\text { th vertex } \mathrm{j}-\text { th edge is incidental } \\
0 \text { when for the } \mathrm{i}-\text { th node the } \mathrm{j}-\text { th edge is not incidental }
\end{array}\right.
$$

The canonical oriented graph represents a system that has an analytic solution. Since not all arrays of destination and dispatching of cargoes by each mode of transport in general will be a canonical graph. Such arrays, in particular, may be non-canonical, that is, in the general case, have no solution in the analytical form. The lack of a solution will not allow a 
formal representation of the target function in the mathematical model being developed. To eliminate this discrepancy, we suggest that the non-canonical graph being converted into a canonical form in a formal way. Imagine a graph like an array of real and fictitious vertices, the relationship between which will be characterized by the values of the time of transportation of the cargo and the cost of this transportation equaling zero. Since transport services, in particular, points of dispatch of goods, their transshipment, points of receipt of cargo of the district, transportation routes [3, 6, 10], etc., are described by sets of parameters, each of which can, in general, represent a matrix of sub-parameters, that is an over-large set of data (big data), an expedient mathematical apparatus for their description would be tensor analysis. Then the orthograph, which combines the orthographs of certain types of transport, can be regarded as a topological structure in the multidimensional space. Using the invariance of a tensor, one can determine the required parameters of a multidimensional digraph structure when changing system of coordinates, for example, when changing the target function of finding an optimal chain of multimodal transport. We represent a non-coordinate formalization of the tensor equation of the specified structure:

$$
W Q=V
$$

where the tensors $W$ and $Q$ describe the parameters of multivariance transport system of multimodal transportation, tensor $V$ may be the throughput of a tree or a separate branch of communication between the graphs of individual modes of transport, in the case when $W-$ is a network connectivity tensor that can be obtained if knowing the incidence tensor of a large system, and $Q-$ characterizes the throughput of a tree or a single branch of communication in the presence of a specific set of transportation risks. Since the risks are stochastic terms that change at certain, defined intervals, then the tensor $V$ may represent the probability of having a throughput for transporting of a specific, determined cargo through the specified branch / communication tree. But this can be if and only if $W$ - the probability of the existence of a flow of goods in certain nodes at certain intervals of time. That is, the given representation may have a deterministic or stochastic nature, depending on the conditions of actual shipments of the goods. This invariance facilitates the solution of the problem while changing the parameters of the cargo flow.

For example, when the objective function is to minimize the time of multimodal transportation, taking into account the probability of deviation of each risk on each branches from the time schedule can be transformed into the tensor $W$-the tensor of cargo delays in individual branches as a result of the existence of specific risks. In this case, the tensor $Q$ still will be considered as the bandwidth of the tree or branch of connection. When the risks are random variables, knowing the law of change in random variable for each specific risk on each individual branch, we can define the correlation coefficient $r$ as an algebraic equation in the form: $r=\varphi(k, D)$, where $k$ - correlation function, $D$ - dispersion of each of the specific risks. The objective function of the suggested model may have a different representation. When the main requirement for transportation is to ensure the minimum total transport costs, then the target function will look like: $F_{\$}=\varphi(\overrightarrow{\mathrm{C}}, \overrightarrow{\mathrm{B}}, \vec{L}, \overrightarrow{\mathrm{E}}) \rightarrow \min$, where $F_{\$}$ - objective function of economic costs, $\overrightarrow{\mathrm{C}}$ - vector cost of transportation of the unit of cargo on each section of the chain of transportation, $\overrightarrow{\mathrm{B}}$ single cargo vector, $\vec{L}$ - vector of specific stages of the transportation chain, $\overrightarrow{\mathrm{E}}-$ vector of mathematical expectations of the effects of risks on each section of the transport chain.

When the main requirement is to ensure a minimum transport time, the target function has the form: $F_{\tau}=\varphi(\overrightarrow{\mathrm{T}}, \vec{L}, \overrightarrow{\mathrm{E}}) \rightarrow \min$, where $F_{\tau}$ - objective delivery function of the cargo, $\overrightarrow{\mathrm{T}}$ - vector of time spent on each stage of cargo transportation. Obviously, the choice of a direction of transportation could be substantiated by the requirements of provision and minimum transport costs, and the least time for cargo transportation. 
The time of cargo transportation can not be greater than that of critical route. Critically, we call the path critical if it needs the maximum time to go through it, even with the time reserved for each of its operations, which are qual to zero. In general case, the ways that satisfy each of the requirements can be different. Then the target function will take a compromise form of minimizing the function of the compromise objective function by minimizing the coinciding paths simultaneously and the economic costs i.e. $F \rightarrow$ $\min \left(F_{\tau}, F_{\$}\right)$ at $L^{\min } \in\left(l_{1}^{\min }, \ldots l_{n}^{\min }\right)$.

Sometimes you have to select, in addition to the mentioned objective functions, the objective function of trust $\left(F_{p}\right)$, which runs along the way with minimal risk of cargo loss. This function may, in some cases, coincide with the level of the insurance premium for damage or loss of cargo.

Many leading specialists are paying attention to this peculiarity of the transport system of the post-Soviet countries, in particular, Jean-Francois Arvi, founder of the LPI project. "In countries with a high level of logistics costs, the main determinant of their magnitude is often not the distance between trading partners, but the reliability of the supply chain", he notes [13]. That is why, there are attempts to disassociate the difficult supply situation with the help of the LPI and, using this index, to characterize supply chains.

In the presence of three objective functions, a compromise function can be found as follows: $F \rightarrow \min \left(F_{\tau}, F_{\$}, F_{p}\right)$.

In case of the influence of risk factors, subject to their stochastic nature, the method [5] can be used to find the optimal value of the target function.

Each specific risk or exposure factor may take valid values and invalid values. When a risk takes a valid value, it varies from an appropriate minimum to the corresponding maximum value. When $E z_{y}$ - mathematical expectation of the influence of accidental risk, respectively, $F\left(E z_{y}\right)$ - integral objective function of transportation, $k=1,2,3 \ldots-$ index of risk in the vector of available risks, $f_{i}$ - a function inherent to the transport on the $i$-th section of the path or edge ( $\operatorname{arc})$ of the corresponding digraph, $i 0 k$ - initial value of the acceptable risk interval, $i 1 k$ - endpoint of the risk tolerance interval $\gamma\left(y, E_{z}, \sigma_{y}\right)$ - density distribution factor $y, \sigma_{y}$ - mean square deviation. That is:

$$
F\left(E z_{y}\right)=\sum_{i=1}^{n} f_{i} \int_{i 0 k}^{i 1 k} \gamma\left(y, E z_{y}, \sigma_{y}\right) d y
$$

When a risk takes a valid value, it varies from an appropriate minimum to the corresponding maximum value. That is $i_{k} \in\left(i_{k}^{\min }, i_{k}^{\max }\right)$. Then the probability of falling into the range of admissible values for each of the risk factors is defined as $\int_{i 0 k}^{i 1 k} \gamma\left(y, E_{z}, \sigma_{y}\right)$.

When choosing a variant of transportation, when calculating the parameters of transportation, the basic option is the smallest value of the magnitude of the mathematical expectation of the effects of random risk, that is, for example, the value $F\left(E z_{y}\right) \rightarrow \min (F)$ under condition of a smooth change of the objective function:

$$
F\left(E z_{y}\right)=\left\{\begin{array}{l}
\max (F) \text { when } \max \left(E z_{y}\right) \\
\min (F) \text { when } \min \left(E_{z_{y}}\right)
\end{array}\right.
$$

When the risk takes valid values, it varies in an interval from a certain minimum to the corresponding maximum value. That is $i_{k} \epsilon\left(i_{k}^{\min }, i_{k}^{\max }\right)$, then the probability of falling 
into the range of admissible levels of each of the risk factors is defined as $\int_{i 0 k}^{i 1 k} \gamma\left(y, E z_{y}, \sigma_{y}\right)$.

The integral objective transportation function is calculated according to a different formula representation, depending on whether it is a continuous function over the entire range of its definition, whether it has discontinuities or discrete one $[7,14,15]$.

A significant number of risk factors that influence the definition of the objective function of transport are fuzzy values. In order to calculate the cost / time of transportation, it is necessary to consider not only the transport costs / loss of time on each of the edges (branches) of the cargo route, but also, for example, the loss of these resources upon the receipt for transportation and transmission to the consumer. Losses at this stage of transportation may arise when the fuzzy values of the impact of transportation of goods/overload of goods on time, volumes, the size of the batches. Anthracite supply to the heat power station in Ukraine can serve as a concrete example. Suppliers from different countries, different modes of transport, delivery, imposed on different speeds of consumption, require maximum synchronization at all stages - beginning with the approaching of empty rail cars to loading up and ending up with changing the size of coal reserves in warehouses suppliers, transshipment warehouses and at the side of consumers. Violation of synchronization leads to losses. For example, when a load of coal was delayed on the road, it leads to losses due to lack of supply, when it came earlier, it increases stock losses. Let's consider, as an example, the task of minimizing economic losses associated with the risks of desynchronization, at the stage of cargo handling. Total freight handling costs consist of a transport component and a component related to storage costs. We represent the costs of cargo handling in analytical form:

$$
S=S_{1}+S_{2}+S_{3}+S_{4}+S_{5}
$$

where $S$ - total handling costs, $S_{1}$ - transportation costs, $S_{2}$ - storage costs, $S_{3}$ - costs associated with cargo lag when maximizing delivery risks, $S_{4}$ - overhead storage costs, $S_{5}$ overload costs (which is important for multimodal transport - from one mode of transport to another).

$$
S_{1}=\sum_{\tau=0}^{\tau_{\max }} \sum_{j_{1}}^{j_{n}} c_{j}(\tau) b_{i j}(\tau)
$$

where $\tau$ - time of transportation, $\tau \in\left(0, \tau_{\max }\right), c_{j}$ - freight cost per unit of cargo, $b_{i j}$ single cargo, the indices of which belong to the interval $j \in\left(j_{1}, j_{n}\right)$. Storage costs can be estimated by

$$
S_{2}=\sum_{\tau=0}^{\tau_{\max }} \sum_{j_{1}}^{j_{n}} a_{j}(\tau) b_{j}(\tau)
$$

where $a_{j}$ - the cost of storage of a unit of cargo. Costs associated with cargo delays when maximizing delivery risks, are determined by terms of contract. For multimodal transport, these costs will also depend on the stage of transportation where the delay occurs. If it is the initial stage, then there will be delays at all subsequent stages $[8,11,16,17,18]$. One can determine the costs associated with cargo lag as:

$$
S_{3}=\sum_{1}^{u} h_{u} * S_{3 u}
$$

where $u$ - number of the transportation stage, $S_{3 u}$ - costs and penalties for the $u$-the stage of transportation, $h_{u}$ - Boolean function that takes values $h_{u}=0$ in the absence of delays, $h_{u}=1$ in the presence of delays. 
Costs associated with cargo delay vary within intervals $S_{3} \in(0, \infty)$. A condition of the occurrence of a situation where non-zero values of costs associated with cargo delay will be in place: $\tau>\tau_{1 f}$, where $\tau$ - current time of the operation of cargo transportation, $\tau_{1 f}$ - the boundary value of delivery time.

In the case $[2,8,19,20,21,22]$, when fines are dependent on the time of delay, an analytical expression for finding the value of the costs associated with the delay of the goods will be:

$$
S_{3}=\int_{1 f}^{\tau_{2}} \sum_{j_{1}}^{j_{n}} c_{j}\left(\left(\tau_{1 f}-\tau_{2}\right) b_{j}\left(\tau_{1 f}-\tau_{2}\right) d \tau\right.
$$

where $\tau_{2}$ - delivery time value, $\mathrm{c}_{j}$ - specific economic losses associated with untimely receipt of a unit of cargo. Additional costs associated with storing the cargo can be found as

$$
S_{4}=\int_{1 f}^{\tau_{2}} \sum_{j_{1}}^{j_{n}} d_{j}\left(\left(\tau_{1 f}-\tau_{2}\right) b_{j}\left(\tau_{1 f}-\tau_{2}\right) d \tau\right.
$$

where $d_{j}$ - specific economic losses associated with the storage of a unit of cargo.

The task set up supposed finding the minimum value of the total cost of transshipment, that is, in analytical form $S \rightarrow S_{\min }$. The effect of untimely receipt of a unit of cargo varies depending on the type of cargo, the consumer's needs, the time of delay, the size of penalties assumed in the contract, which may depend on the parameters mentioned and be their non-discrete or discrete function.

Therefore, the result of minimizing the total costs of transshipment can be as finding the optimal time interval of delay, corresponding to the condition $S\left(\tau_{1 f}-\tau_{2}\right)=S_{\min }$ when $\left(\tau_{1 f}-\tau_{2}\right)=\left(\tau_{1 f}-\tau_{2}\right)_{\text {min }}$, as well as reducing the risk of delivery or penalties for late delivery of cargo, which is in line with the condition $\tau \leq \tau_{1 f}$. Overhead costs vary in interval $S_{5} \in\left(S_{5 \text { min }}, S_{5 \text { max }}\right)$. $S_{5 \text { max }}$ value, in particular, depends on the presence of cargo delays during the transportation phase, because it increases the cost of rolling stock and services of the next stage of transportation. For the analysis and evaluation of the reliability of contractors, the type of transport on the route, etc., the parameters of delivery of each cargo are required. For example, the average delivery time, the deviation from the average (upper and lower limits), the level of prices for services, the quality of services, the level of prices for cargo, quality of goods, timeliness (number and timing of violation of timeliness), etc.

Depending on the qualitative estimation of the set of these parameters, an auxiliary database is created for the categories of delivery: the use for each type of cargo, only for logistics operations with the objective delivery function subject to time, only for logistics operations with the objective delivery function subject to cost (for example, for formation of warehouse reserves, in particular, coal for heat-power stations) [9, 19, 23-26]. Formation of such an auxiliary database by categories of delivery allows to save time of calculations and resources of computer equipment [27-30].

The test of this mathematical model was the analysis of the transportation of grain cargoes from the city of Kremenchug to the port of Odessa. This made it possible to reveal the most problematic areas of grain handling. Such areas are: points of overload from one mode of transport to another, transportation by rail, issues of tariff policy of carriersmonopolies, regulatory risks of cargo transportation. It was established that alternative transportation of goods by rail can be used on separate sections of river transport, which will slightly (up to $5 \%$ ) increase the cost of transportation of grain but will significantly reduce the risks. 


\section{Conclusions}

In this paper, a mathematical model of SPDR for multimodal transport is suggested for countries with a high level of logistics losses, with a set of risks of cargo transportation, much larger than in developed countries. Its test usage indicated weaknesses in the supply chains of Ukraine. These are the transshipment of multimodal cargoes, rail transport, seasonal road transport risks, regulatory and tariff policies. Due to the lack of time, it is needed to make a certain number of adaptations, implementation in the test code of the test launches on large masses of real data with the subsequent verification of the predictions for relevancy. Future work relates to the details of certain parts of the mathematical model, the development of packages for individual variants of the event tree. In addition, since the use of SPDR involves the use of large data arrays in algorithmic mathematical model, it is necessary to predict its parallel work in multiprocessor systems. The analysis of the situation of cargo transportation, in particular, multimodal transport with the help of the presented mathematical device, allowed to reveal that the most significant problem is not the stage of cargo transportation (by this or that mode of transportation), but the stage of overload.

\section{References}

1. Harris, I., Wang, Y., \& Wang, H. (2015). IST in multimodal transport and technological trends: Unleashing potential for the future. Int. J. Production Economics, 159, 88-103.

2. Schilk, G., \& Seemann, L. (2012). Use of ITS technologies for multimodal transport operations - River Information Services (RIS) transport logistics services. Procedia Social and Behavioral Sciences, 48, 622-631. https://doi.org/10.1016/j.procs.2019.09.406

3. Baptista, P., Azevedob, I.L., \& Fariasa, T.L. (2012). ICT solutions in transportation systems: estimating the benefits and environmental impacts in the Lisbon. Procedia $\begin{array}{llll}\text { Social and } \quad \text { Behavioral } & \text { 516-725. }\end{array}$ https://doi.org/10.1016/j.sbspro.2012.09.789

4. Kotenko, S., Nitsenko, V., Hanzhurenko, I., \& Havrysh, V. (2020). The Mathematical Modeling Stages of Combining the Carriage of Goods for Indefinite, Fuzzy and Stochastic Parameters. International Journal of Integrated Engineering, 12(7), 173-180. https://doi.org/10.30880/ijie.2020.12.07.019

5. Andriushchenko, K., Lavruk, V., Uliganets, S., Kovtun, V., \& Matviienko, H. (2019). Reputation Risk Management Companies Based on Competence Approach. TEM Journal, 8(2), 516-524. https://doi.org/10.18421/TEM82-27

6. Kostenko, I. (2020). Current Problems and Challenges in International Space Law: Legal Aspects. Advanced Space Law, 5, 48-57. https://doi.org/10.29202/asl/2020/5/5

7. Kholiavko, N., Popova, L., Marych, M., Hanzhurenko, I., Koliadenko, S., \& Nitsenko, V. (2020). Comprehensive methodological approach to estimating the research component influence on the information economy development. Naukovyi Visnyk Natsionalnoho Hirnychoho Universytetu, 4, 192-199. https://doi.org/10.33271/nvngu/2020-4/192

8. Agamirzyan, I., Belousov, D., Kuznetsov, E., Zotov, A., Danilin, I., Kholkin, D., Proydakov, E., Raevskiy, A., \& Pervushin, A. (2016). Challenge 2035. Moscow Olimp-Biznes.

9. Krasnobaev, V., Zub, M., Kuznetsova, T., Perevozova, I., \& Maliy, O. (2019). Mathematical Model of the Process of Tabular's Implementation of the Operation Algebraic Multiplication in the Residues Class. International Conference on 
Information and Telecommunication Technologies and Radio Electronics (UkrMiCo). Odessa, Ukraine, 1-6, https://doi.org/10.1109/UkrMiCo47782.2019.9165400

10. Nikishov, S.I. (2017). The use of a fuzzy composition to simulate logistic flows. Russian Journal of Innovation Economics, 7(3), 247-256. https://doi.org/10.18334/vinec.7.3.38197

11. Khomenko, I., \& Bura, K. (2020). Aggressiveness in Interpersonal Arguing from Multimodal Argumentation View. Ukrainian Policymaker, 7, 28-34. https://doi.org/10.29202/up/7/4

12. Yankovyi, O., Goncharov, Y., Koval, V., \& Lositska, T. (2019). Optimization of the capital-labor ratio on the basis of production functions in the economic model of production. Naukovyi Visnyk Natsionalnoho Hirnychoho Universytetu, 4, 134-140. https://doi.org/10.29202/nvngu/2019-4/18

13. Mizraji, E. (1992). Vector logics: The matrix-vector representation of logical calculus. Fuzzy Sets and Systems, 50(2), 179-185. https://doi.org/10.1016/0165-0114(92)90216$\underline{\mathrm{Q}}$

14. Nitsenko, V., Kotenko, S., Hanzhurenko, I., \& Ingram, K.L. (2020). Determination of Weight Coefficients for Stochastic and Fuzzy Risks for Multimodal Transportation. Journal of Physics: Conference Series, 1529, 032007. https://doi.org/10.1088/1742$\underline{6596 / 1529 / 3 / 032007}$

15. Giza, F., \& Zaytsev, A.A. (2015). Integration of supply chain management subsystem in the innovative activities of high-tech enterprises. Issues of innovative economy, 3 , 63-78. https://doi.org/10.18334/inec.5.3.587

16. Guba, K.A., \& Dyubanov, G.N. (2013). Optimizing warehouse logistics through fuzzy logic device. The World of economics and management, 13(3), 14-18

17. Danyliuk, V., Riepina, I., Shafalyuk, O., Kovylina, M., \& Nitsenko, V. (2020). Functional and investment strategies of technical development of enterprises. Naukovyi Visnyk Natsionalnoho Hirnychoho Universytetu, 3, 115-121. https://doi.org/10.33271/nvngu/2020-3/115

18. Perevozova, I., Andryushchenko, I., Vysotska, M., Vasyliev, A., \& Krivorotenko, L. (2019). Introduction of strategic management technology into the existing organizational and economic mechanism of the enterprise. Academy of Strategic Management Journal, 18(1). http://eir.zntu.edu.ua/handle/123456789/5623

19. Shmygol, N., Schiavone, F., Trokhymets, O., Pawliszczy, D., Koval, V., Zavgorodniy, R., \& Vorfolomeiev A. (2020). Model for assessing and implementing resourceefficient strategy of industry. CEUR Workshop Proceedings, 2713, 277-294.

20. Nguyen, N.T. (2020). Marine Culture of Northeast Vietnam: Approaching from the Theory of Culture Ecology. Future Human Image, 13, 66-75. https://doi.org/10.29202/fhi/13/7

21. Kovtun, V., Andriushchenko, K., Horbova, N., Lavruk, O., \& Muzychka, Y. (2020). Features of the Management Process of Ambidextrous Companies. TEM Journal, 9(1), 221-226. https://doi.org/10.18421/TEM91-31

22. The World Bank Group (2014). Logistics Performance Index (LPI) Report: The Gap Persists. $\quad$ http://www.worldbank.org/en/news/press-release/2014/03/20/logisticsperformance-index-gap-persists

23. Nitsenko, V., Kotenko, S., Hanzhurenko, I., Mardani, A., Stashkevych, I., \& Karakai, M. (2020). Mathematical Modeling of Multimodal Transportation Risks. 439-447. In: Ghazali R., Nawi N., Deris M., Abawajy J. (eds) Recent Advances on Soft Computing and Data Mining. SCDM 2020. Advances in Intelligent Systems and Computing, 978. Springer, Cham. https://doi.org/10.1007/978-3-030-36056-6 41 
24. Hutsaliuk, O., Koval, V., Tsimoshynska, O., Koval, M., \& Skyba, H. (2020). Risk Management of Forming Enterprises Integration Corporate Strategy. TEM Journal, 9(4), 1514-1523. https://doi.org/10.18421/TEM94-26

25. Sakhno, A., Hryvkivska, O., Salkova, I., \& Kucher, L. (2019). Evaluation of the efficiency of enterprises by the method of analysis of functioning environment. Journal of Environmental Management and Tourism, X, 3(35), 499-507. https://doi.org/10.14505/jemt.v10.3(35).04

26. Kalinichenko, A., Havrysh, V., \& Perebyynis, V. (2017). Sensitivity analysis in investment project of biogas plant. Applied ecology and environmental research, 15(4), 969-985. http://dx.doi.org/10.15666/aeer/1504 969985

27. Kalinichenko, A., \& Havrysh, V. (2019). Feasibility study of biogas project development: technology maturity, feedstock, and utilization pathway. Archives of Environmental Protection, 45(1), 68-83. https://doi.org/10.24425/aep.2019.126423

28. Dankeieva, O., Solomianiuk, N., Strashynska, L., Fiedotova, N., Soloviova, Y., \& Koval, V. (2021). Application of Cognitive Modelling for Operation Improvement of Retail Chain Management System. TEM Journal, 10(1), 358-367. https://doi.org/10.18421/TEM101-45

29. Latysheva, O., Rovenska, V., Smyrnova, I., Nitsenko, V., Balezentis, T., \& Streimikiene, D. (2020). Management of the sustainable development of machinebuilding enterprises: a sustainable development space approach. Journal of Enterprise Information Management, 34(1), 328-342. https://doi.org/10.1108/JEIM-12-2019-0419

30. Chukurna, O., Nitsenko, V., Kralia, V., Sahachko, Y., Morkunas, M., \& Volkov, A. (2019). Modelling and Managing the Effect of Transferring the Dynamics of Exchange Rates on Prices of Machine-Building Enterprises in Ukraine. Polish Journal of Management Studies, 19(1), 117-129. https://doi.org/10.17512/pjms.2019.19.1.09 